\title{
Significance of serum procalcitonin as biomarker for detection of bacterial peritonitis: a systematic review and meta-analysis
}

\author{
Shi-kun Yang ${ }^{1 \dagger}$, Li Xiao ${ }^{1 \dagger}$, Hao Zhang ${ }^{2}$, Xiao-xuan Xu ${ }^{1}$ Pan-ai Song ${ }^{1}$, Fu-you Liu ${ }^{1}$ and Lin Sun ${ }^{1 *}$
}

\begin{abstract}
Background: Bacterial peritonitis is serious disease and remains a diagnostic challenge for clinicians. Many studies have highlighted the potential usefulness of procalcitonin (PCT) for identification of bacterial peritonitis, however, the overall diagnostic value of PCT remains unclear. Therefore, we performed a meta-analysis to assess the accuracy of PCT for detection of bacterial peritonitis.

Methods: We performed a systematic searched in MEDLINE, EMBASE, SCOPUS, China Biology Medicine Database (CBM), China National Knowledge Infrastructure Database (CNKI) and Cochrane databases for trials that evaluated the diagnostic role of PCT for bacterial peritonitis. Sensitivity, specificity and other measures of accuracy of PCT were pooled using bivariate random effects models.

Results: Eighteen studies involving 1827 patients were included in the present meta-analysis. The pooled sensitivity and specificity of serum PCT for the diagnosis bacterial peritonitis were 0.83 ( $95 \%$ Cl: $0.76-0.89$ ) and 0.92 (95\% Cl: 0.87-0.96), respectively. The positive likelihood ratio was 11.06 (95\% Cl: 6.31-19.38), negative likelihood ratio was 0.18 (95\% Cl: 0.12-0.27) and diagnostic odds ratio (DOR) was 61.52 (95\% Cl: 27.58-137.21). The area under the receiver operating characteristic curve (AUROC) was 0.94. Use of a common PCT cut-off value could improve the DOR to 75.32 and the AUROC to 0.95. Analysis of the seven studies that measured serum C-reactive protein (CRP) indicated that PCT was more accurate than CRP for the diagnosis of bacterial peritonitis.

Conclusions: Our results indicate that PCT determination is a relatively sensitive and specific test for the diagnosis of bacterial peritonitis. However, with regard to methodological limitations and significant heterogeneity, medical decisions should be based on both clinical findings and PCT test results.
\end{abstract}

Keywords: Procalcitonin, Diagnosis, Peritonitis, Meta-analysis

\section{Background}

Bacterial peritonitis is an inflammation of the peritoneum by micro-organisms such as Gram negative bacilli. The mortality of peritonitis in the early 1900 s was close to $90 \%$. With the introduction of various antibiotics, the mortality continued to decrease slowly [1]. However, it is still a common illness that adversely affects the prognosis, and increases costs to health-care systems worldwide. It frequently occurs in children and adults, and can endanger life, particularly in patients who have

\footnotetext{
*Correspondence: zndxsunlin11@163.com

${ }^{\dagger}$ Equal contributors

'Department of Nephrology, The Second Xiangya Hospital, Kidney Institute of Central South University, Changsha, Hunan 410011, China

Full list of author information is available at the end of the article
}

decompensated cirrhosis or in patients receiving continuous ambulatory peritoneal dialysis therapy. Previous studies showed an average peritonitis rate of 1 episode per 24.5 patient treatment months for continuous ambulatory peritoneal dialysis [2]. While the prevalence of bacterial peritonitis in cirrhotic patients with ascites admitted to hospital ranges ranging $10 \%$ to $30 \%$ [3]. It has been proven that delayed diagnosis of peritonitis was an important factor for its high mortality, Consequently, diagnosis of bacterial peritonitis continues to be a major clinical challenge, and an accurate biomarker for the early identification of peritonitis would be of great diagnostic value.

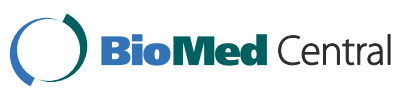

(c) 2014 Yang et al.; licensee BioMed Central Ltd. This is an Open Access article distributed under the terms of the Creative Commons Attribution License (http://creativecommons.org/licenses/by/2.0), which permits unrestricted use, distribution, and reproduction in any medium, provided the original work is properly credited. The Creative Commons Public Domain Dedication waiver (http://creativecommons.org/publicdomain/zero/1.0/) applies to the data made available in this article, unless otherwise stated. 
Several potential biomarkers have been proposed in highly cited studies for their ability to diagnose bacterial infections, procalcitonin (PCT), which is a precursor of calcitonin including 116-aminoacid polypeptide has been indicated the "the champion" so far [4]. It is undetectable $(<0.01 \mathrm{ng} / \mathrm{ml})$ in normal conditions, while in cases of infection, it increases rapidly produced by extrathyroidal cells (e.g. monocytes) [5]. There is a significant body of clinical research indicating a good diagnostic accuracy for the PCT test for discrimination between invasive fungal infection and bacterial infection or noninfectious conditions [4,6]. However, only one systematic review has investigated the accuracy of PCT for the diagnosis of spontaneous bacterial peritonitis [7], with limitation of the small number of trials included. Additionally, several new studies of PCT have been published and our knowledge of PCT is still developing. Therefore, we undertook the present meta-analysis and systemic review mainly to quantitatively summarize the current evidence on the value of PCT as a marker of bacterial peritonitis. Because there is no consensus about the appropriate PCT cut-off level to predict bacterial peritonitis, and as different PCT thresholds have been used between studies, we calculated the summary receiver operating characteristic (ROC) curves approach to perform this analysis [8].

\section{Methods}

\section{Data sources and search strategy}

This meta-analysis was performed according to the meta-analysis of observational studies in epidemiology reporting guidelines [9]. We performed a literature search in MEDLINE, EMBASE, SCOPUS, Cochrane databases, China Biology Medicine Database (CBM), and China National Knowledge Infrastructure (CNKI) Database (all to April 2014) adhering to PRISMA guidelines to identify eligible studies. The following search terms were used: procalcitonin, $\mathrm{PCT}$, peritonitis, ascites, peritoneal, abdominal cavity, infection in combination with biomarker (Figure 1 shows details of the search method used in this meta-analysis). Published studies were sought initially without language restrictions. The patients with any active infection in other organs or sites, active immune disease, or cancer were excluded. We also reviewed the reference lists of the original and review articles in order to identify other potentially relevant trials.

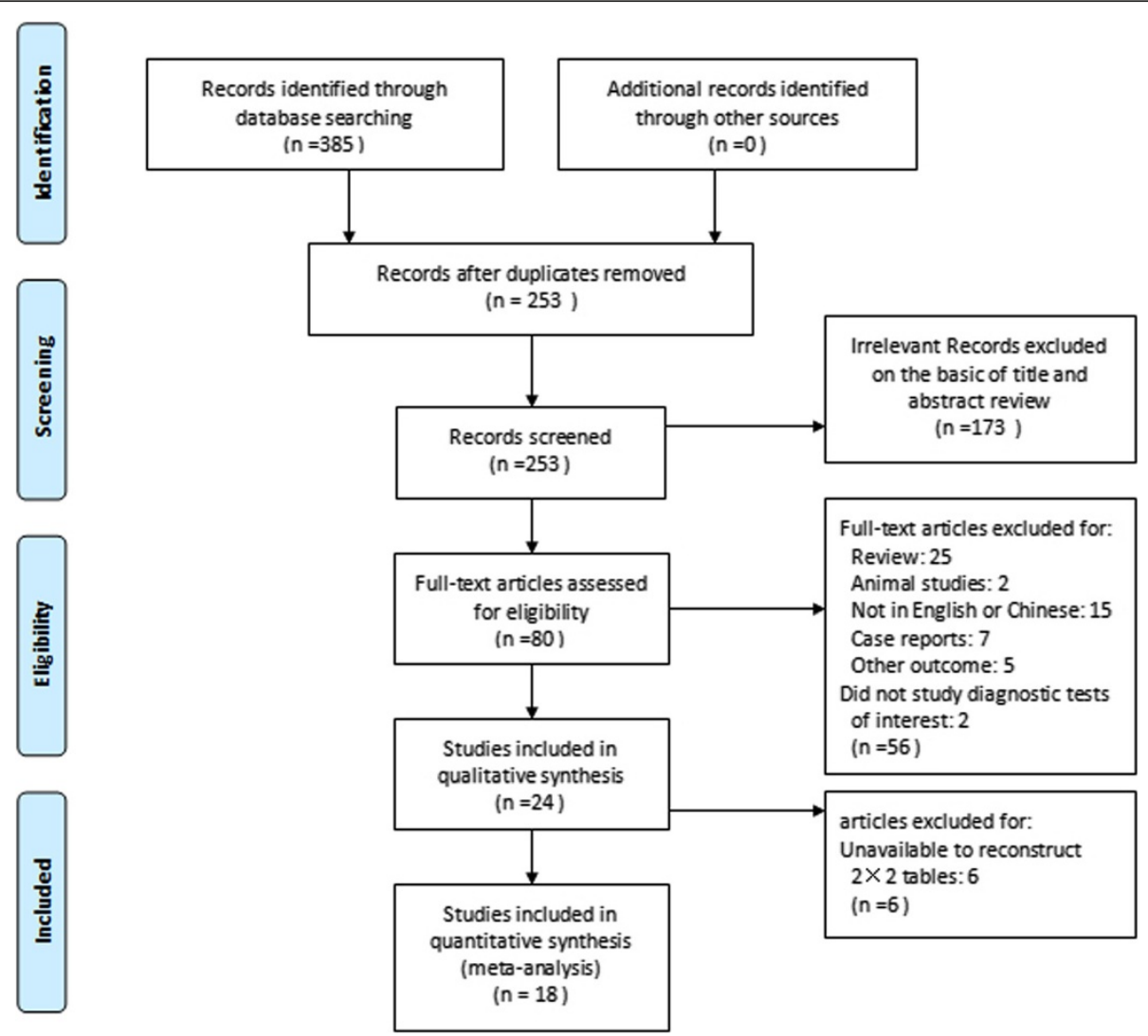

Figure 1 Flow diagram of study identification and inclusion. 


\section{Study selection}

Only studies that investigated the diagnostic accuracy of PCT level to predict peritonitis in humans were considered for inclusion in this meta-analysis. We included prospective and retrospective studies. For the full-text review and the final analysis, we only included articles published in English and Chinese although there was no language restrictions. We excluded case reports, conference abstracts, review and letters to journal editors. Three of the authors (S. K.Y. L.X and P.A.S.) independently evaluated the titles and abstracts, and excluded all studies that were clearly not relevant with the inclusion criteria, then three authors (S.K.Y., P.A.S. and L.X.) assessed the full-text articles independently. We presented the reasons for study exclusion and progress in Figure 1.

\section{Data extraction and quality assessment}

The following data were extracted or recalculated: year of publication, country of origin, sample size, patients ages, study design, PCT testing systems, specificity and sensitivity. The data of $2 \times 2$ tables (truepositive, false-positive false-negative and true-negative) were calculated for meta-analysis. These data were extracted independently by two authors (S.K.Y. and P.A. S.), and in cases of missing data, we contacted the corresponding author by e-mails in order to seek the required information. We used the Quality Assessment of Diagnostic Accuracy Studies (QUADAS) criteria to assess the quality of included studies [10]. When different sensitivity or specificity values were reported in a study at different cutoffs, the data with the highest Youden index was used for meta-analysis [11]. Then the data of $2 \times 2$ tables were entered into Stata 12.0 by S.K.Y. and the data entry was checked by X.X.X.

\section{Data synthesis and statistical analysis}

The meta-analyses were performed using Stata,version 12.0 (Stata Corp., College Station, TX, USA) [12], notably with the "midas" and "metandi" commands. We calculated the pooled sensitivity and specificity, diagnostic odds ratio (DORs) and the likelihood ratio et al. based on the bivariate random effect models for meta-analysis of diagnostic test data [13]. In case multiple cut-off points for PCT analysis were provided in a same study, we choose the cut-off giving the maximum overall accuracy. We also constructed the respective summary receiver operating characteristic curves(SROC) and calculated the area under the receiver operating characteristic curve (AUROC), irrespective of different cut-off points used [14]. Heterogeneity was quantitatively assessed using the $I^{2}$ statistic $\left(I^{2}\right.$ value $>50 \%$ means a moderate to high heterogeneity) [15]. Remarkable heterogeneity was explored further by subgroup analysis. All statistical tests were two-sided and statistical significance was defined as $\mathrm{P}<0.05$. To test for possible publication bias, we constructed effective sample size funnel plots versus the log diagnostic odds ratio and did a regression test of asymmetry (Deek's test), with $\mathrm{P}<0.05$ for the slope coefficient indicating significant publication bias [16].

\section{Results}

\section{Identification of studies}

Overall, Our electronic search yielded 385 published studies, of which 305 studies irrelevant to this review were excluded after screening titles and abstracts. Having reviewed the full text of the remaining 80 articles, we then excluded another 62 studies: among them, 25 was review article; 7 was case reports; 2 was animal studies, 7 did not investigate the diagnostic value of serum PCT level or explore other outcomes; and 15 was not English or Chinese in the text; and 6 studies was unable to reconstruct $2 \times 2$ tables. Finally, 18 eligibility studies were included in the analysis [17-34] [Figure 1].

\section{Study characteristics}

The main characteristics of included studies were summarized in Table 1.

Nine studies were published in English [17-25], and nine in Chinese [26-34], representing an international experience from 5 countries. There were two trials performed by the same research unit $[26,29]$, but the patients in these two studies were recruited from different cohorts. Overall, 1827 patients were enrolled. All studies were conducted in adult patients. 4 of them referred to peritonitis in peritoneal dialysis patients [17-20], 12 studies reported spontaneous bacterial peritonitis in cirrhotic patients [21-23,25-32,34], 1 study were from spontaneous bacterial peritonitis of chronic severe hepatitis patients [24], and 1 study was from spontaneous bacterial peritonitis of end stage liver disease patients [33]. Fourteen studies [21-34] used ascitic polymorphonuclear(PMN) cells $>250 / \mathrm{mm}^{3}$, while four studies [17-20] used ascitic PMN $>50 / \mathrm{mm}^{3}$ as the reference diagnostic standard for peritonitis. Common bacteria isolated were Escherichia coli, and Streptococcus species. PCT levels were measured in serum sample in 17 studies [17-27,29-34] and in ascites fluid sample in 5 studies [22,23,28,29,34], mostly using the LUMI test kit (BRAHMS, Berlin, Germany) and Semiquantitative PCT-Q testing assays.

\section{Quality assessment}

The QUADAS tool was used for study quality assessment, and Figure 2 provided an overall impression of the quality of the included studies. Five of 18 included studies were prospective $[17,18,22,23,25]$, and 13 studies 
Table 1 Characteristics of included studies

\begin{tabular}{|c|c|c|c|c|c|c|c|c|c|c|c|c|c|}
\hline $\begin{array}{l}\text { Author, year, } \\
\text { country }\end{array}$ & Design & $\begin{array}{l}\text { Mean age (years) } \\
\text { Case/control }\end{array}$ & $\begin{array}{l}\text { Patient } \\
\text { group }\end{array}$ & $\begin{array}{l}\text { Case/ } \\
\text { control }\end{array}$ & $\begin{array}{l}\text { Outcomes } \\
\text { definition }\end{array}$ & $\begin{array}{l}\text { Biomarkers } \\
\text { tested }\end{array}$ & Cut-off $^{\#}$ & $\begin{array}{l}\text { Sensitivity, } \\
\text { specificity }\end{array}$ & $\operatorname{TP}(n)$ & $\mathrm{FP}(\mathrm{n})$ & $\mathrm{FN}(\mathrm{n})$ & $\mathrm{TN}(\mathrm{n})$ & PCT testing assays (FAS of PCT assays) \\
\hline Cekin, 2013 [21] & Retrospective & 63.4 & Cirrhotic & $59 / 24$ & SBP & Serum PCT & 0.42 & $78 \%, 75 \%$ & 46 & 6 & 13 & 18 & ECLIA $(0.5 \mathrm{ng} / \mathrm{ml})$ \\
\hline \multicolumn{14}{|l|}{ Turkey } \\
\hline Connert, 2003 [25] & Prospective & 57 & Cirrhotic & $19 / 81$ & SBP & Serum PCT & 0.615 & $94.7 \%, 70.4 \%$ & 18 & 24 & 1 & 57 & LUMI test $(0.07$ ng/ml) \\
\hline \multicolumn{14}{|l|}{ Germany } \\
\hline Guz, 2006 [17], & Prospective & 46.6 & PD & $21 * / 35$ & PDRP & Serum PCT & 0.5 & $62 \%, 94 \%$ & 13 & 2 & 8 & 33 & LUMI test $(0.02$ ng/ml) \\
\hline \multirow[t]{3}{*}{ Turkey } & & & & & & Serum PCT & 0.75 & $43 \%, 98 \%$ & 9 & 1 & 12 & 34 & \\
\hline & & & & & & Serum PCT & 1.5 & $38 \%, 99 \%$ & 8 & 0 & 13 & 35 & \\
\hline & & & & & & Serum CRP & 6 & $95 \%, 67 \%$ & 20 & 12 & 1 & 23 & \\
\hline Lai, 2013 [27] & Retrospective & $58.2 / 55.9$ & Cirrhotic & $45 / 45$ & SBP & Serum PCT & 0.5 & $83 \%, 81 \%$ & 37 & 9 & 8 & 36 & ECLIA $(0.5$ ng/ml) \\
\hline China & & & & & & Serum CRP & 10 & $75 \%, 63 \%$ & 34 & 17 & 11 & 28 & \\
\hline Lam, 2008 [18], & Prospective & 63.8 & PD & $35 / 165$ & PDRP & Serum PCT & 0.5 & $80 \%, 92 \%$ & 28 & 13 & 7 & 152 & LUMI test $(0.06$ ng/ml) \\
\hline \multicolumn{14}{|l|}{ Hong Kong } \\
\hline Liu, 2006 [31] & Retrospective & $52 / 42$ & Cirrhotic & $17 / 20$ & SBP & Serum PCT & 0.5 & $100 \%, 100 \%$ & 17 & 0 & 0 & 20 & Semi-quantitative PCT-Q $(0.5$ ng/ml) \\
\hline \multicolumn{14}{|l|}{ China } \\
\hline Liu, 2012 [32] & Retrospective & $45.8 / 43.8$ & Cirrhotic & $55 / 45$ & SBP & Serum PCT & 0.5 & $91 \%, 100 \%$ & 50 & 0 & 5 & 45 & Semi-quantitative PCT-Q $(0.5$ ng/ml) \\
\hline \multicolumn{14}{|l|}{ China } \\
\hline Öztürk, 2010 [20] & Retrospective & $49.0 / 44.8$ & PD & $50 / 50$ & PDRP & Serum PCT & 0.5 & $42 \%, 84 \%$ & 21 & 8 & 29 & 42 & Semi-quantitative PCT-Q $(0.5$ ng/ml) \\
\hline \multirow[t]{3}{*}{ Turkey } & & & & & & Serum PCT & 2 & $14 \%, 100 \%$ & 7 & 0 & 43 & 50 & \\
\hline & & & & & & Serum CRP & 50 & $40 \%, 100 \%$ & 20 & 0 & 30 & 50 & \\
\hline & & & & & & Serum CRP & 8 & $90 \%, 11.9 \%$ & 45 & 44 & 5 & 6 & \\
\hline Spahr, 2001 [22], & Prospective & $58.1 / 57.9$ & Cirrhotic & $10 / 10$ & SBP & Serum PCT & 0.615 & $50 \%, 90 \%$ & 5 & 1 & 5 & 9 & LUMI test $(0.07$ ng/ml) \\
\hline Switzerland & & & & & & Ascitic PCT & 0.5 & $30 \%, 100 \%$ & 3 & 0 & 7 & 10 & \\
\hline Viallon, 2000 [23] & Prospective & $58.8 / 57.6$ & Cirrhotic & $21 / 40$ & SBP & Serum PCT & 0.76 & $95 \%, 98 \%$ & 20 & 1 & 1 & 39 & LUMI test $(0.07$ ng/ml) \\
\hline \multirow[t]{2}{*}{ France } & & & & & & Serum CRP & 80 & $62 \%, 92 \%$ & 13 & 3 & 8 & 37 & \\
\hline & & & & & & Ascitic PCT & 0.3 & $95 \%, 85 \%$ & 20 & 6 & 1 & 34 & \\
\hline Wu, 2014 [33] & Retrospective & $50.8 / 53.0$ & ESLD & 178/184 & SBP & Serum PCT & 0.443 & $84.3 \%, 92.7 \%$ & 150 & 14 & 28 & 170 & Immunoluminometric assay $(0.1 \mathrm{ng} / \mathrm{ml})$ \\
\hline \multirow[t]{2}{*}{ China } & & & & & & Serum PCT & 0.462 & $83.7 \%, 94.9 \%$ & 149 & 10 & 29 & 174 & \\
\hline & & & & & & Serum PCT & 0.500 & $81.0 \%, 96.1 \%$ & 144 & 7 & 34 & 177 & \\
\hline Xie, 2014 [34] & Retrospective & $28-71$ & Cirrhotic & $56 / 36$ & SBP & Serum PCT & 0.5 & $89.3 \%, 94.4 \%$ & 50 & 2 & 6 & 34 & ECLIA $(0.5 \mathrm{ng} / \mathrm{ml})$ \\
\hline China & & & & & & Ascitic PCT & 0.5 & $71.4 \%, 100 \%$ & 40 & 0 & 16 & 36 & \\
\hline Yang, 2007 [28] & Retrospective & $42.4 / 43.4$ & Cirrhotic & 97/86 & SBP & Ascitic PCT & 10 & $92.8 \%, 96.5 \%$ & 90 & 3 & 7 & 83 & Immunoluminometric assay $(0.1 \mathrm{ng} / \mathrm{ml})$ \\
\hline
\end{tabular}


Table 1 Characteristics of included studies (Continued)

\begin{tabular}{|c|c|c|c|c|c|c|c|c|c|c|c|c|c|}
\hline Yilmaz, 2007 [19] & Retrospective & $51.3 / 50.7$ & PD & $20 / 20$ & PDRP & Serum PCT & 0.5 & $70 \%, 100 \%$ & 14 & 0 & 6 & 20 & Semi-quantitative PCT-Q (0.5 ng/ml) \\
\hline Turkey & & & & & & Serum CRP & 8 & $100 \%, 55 \%$ & 20 & 9 & 0 & 11 & \\
\hline Yuan, 2013 [24] & Retrospective & $55.9 / 54.8$ & $\mathrm{CSHB}$ & $42 / 42$ & SBP & Serum PCT & 0.48 & $95 \%, 79 \%$ & 40 & 9 & 2 & 33 & Automated Immunoanalysis $(0.04 \mathrm{ng} / \mathrm{ml})$ \\
\hline \multirow[t]{3}{*}{ China } & & & & & & Serum PCT & 0.67 & $36 \%, 98 \%$ & 15 & 1 & 27 & 41 & \\
\hline & & & & & & Serum CRP & 11.6 & $86 \%, 69 \%$ & 36 & 13 & 6 & 29 & \\
\hline & & & & & & Serum CRP & 16.1 & $64 \%, 95 \%$ & 27 & 2 & 15 & 40 & \\
\hline Zhang, 2004 [29] & Retrospective & 51.4 & Cirrhotic & $41 / 21$ & SBP & Serum PCT & 13.7 & $87.8 \%, 100 \%$ & 36 & 0 & 5 & 21 & Immunoluminometric assay (0.1ng/ml) \\
\hline China & & & & & & Ascitic PCT & 9.5 & $70.7 \%, 80.9 \%$ & 29 & 4 & 12 & 17 & \\
\hline Zhang, 2010 [30] & Retrospective & 58.0 & Cirrhotic & $34 / 39$ & SBP & Serum PCT & 2 & $79.4 \%, 89.7 \%$ & 27 & 4 & 7 & 35 & Semi-quantitative PCT-Q (0.5 ng/ml) \\
\hline China & & & & & & Serum CRP & 8 & $55.2 \%, 86.7 \%$ & 19 & 5 & 15 & 34 & \\
\hline Zhang, 2003 [26] & Retrospective & 48.6 & Cirrhotic & $38 / 51$ & SBP & Serum PCT & 10 & $84.2 \%, 94.1 \%$ & 32 & 3 & 6 & 48 & Semi-quantitative PCT-Q $(0.5$ ng/ml) \\
\hline
\end{tabular}

Note: PD peritoneal dialysis, PDRP peritoneal dialysis-related peritonitis, FAS functional assay sensitivities, PCT Procalcitonin, CRP C-reactive protein, SBP Spontaneous bacterial peritonitis, ECLIA electrochemiluminescence immunoassay, CSHB Chronic severe hepatitis, ESLD end-stage liver disease.

${ }^{\#} \mathrm{PCT}, \mathrm{ng} / \mathrm{ml} ; \mathrm{CRP}, \mathrm{mg} / \mathrm{l}$, *16 PD patients had 21 episodes of PD peritonitis during the study period. 


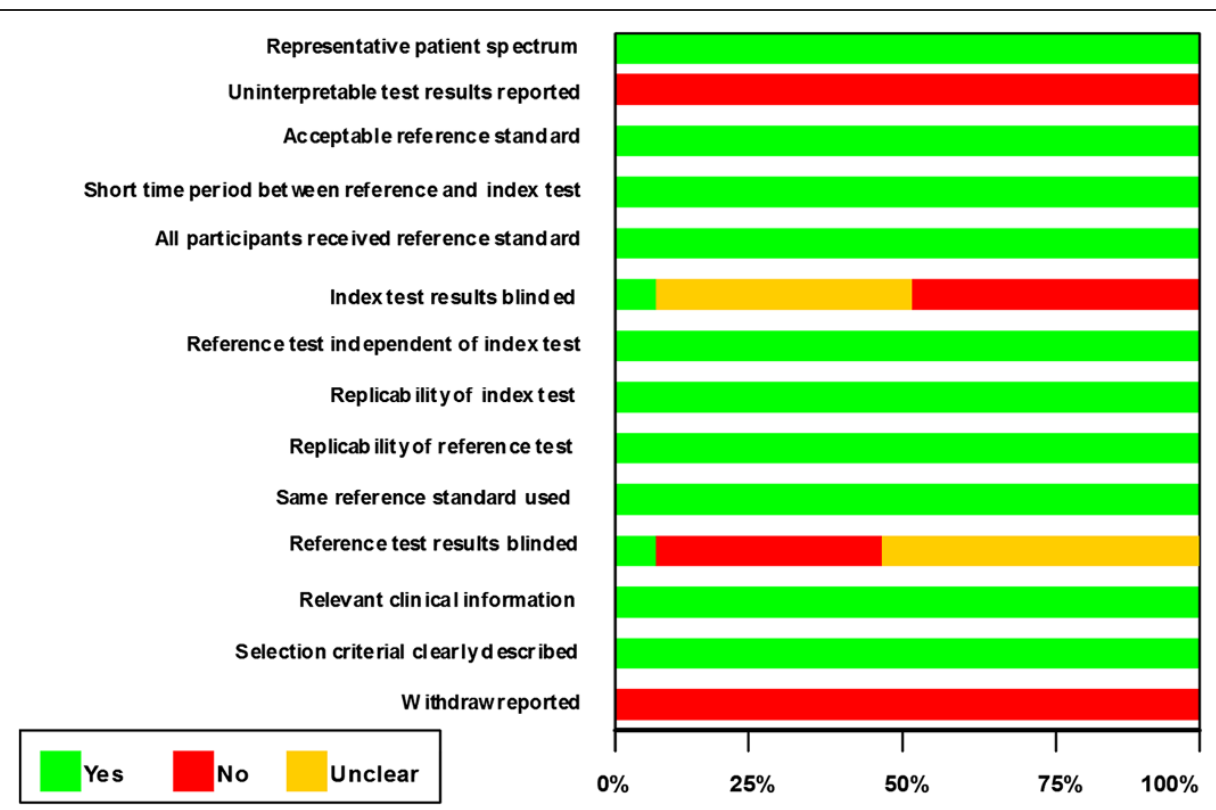

Figure 2 QUADAS (Quality Assessment of Diagnostic Accuracy Studies) criteria for included studies.

were retrospective in design [19-21,24,26-34]. All studies had clearly defined inclusion and exclusion criteria. All of these studies used ascitic polymorphonuclear (PMN) cells count, however, as different definitions were used in different trials, which might lead to potential spectrum bias existed.

None of included trials reported withdrawals or uninterpretable result. Eleven studies did not state whether the PCT results were interpreted without knowledge of outcome assessment $[17,18,21,24,28-34]$, it was poorly reported whether the reference standard results were interpreted blindly, and in only one study, the researchers were blinded to the index test while verifying results by reference standard [23]. These issues might lead to overstated measures of diagnostic accuracy, which is known as a review bias.

\section{Data extraction and calculation}

We calculated the numbers of true-positive, false-positive, false-negative and true-negative based on the provided indexes of sensitivity, specificity, and sample size values. PCT measurement was performed at the beginning of the trial in most of the included studies. We reported the PCT and C-reactive protein (CRP) cut-off values in Table 1. Cut-off values for serum or ascitic PCT varied between studies, ranging from $0.42-13.7 \mathrm{ng} / \mathrm{ml}$, or $0.3-10 \mathrm{ng} / \mathrm{ml}$, respectively.

\section{Diagnostic accuracy indices}

A total of seventeen studies [17-27,29-34] have investigated the diagnostic value of PCT in serum. Our analysis indicated that serum PCT has a high degree of accuracy for the diagnosis of peritonitis. Pooled sensitivity and specificity estimates of PCT were 0.83 (95\% CI: 0.760.89), 0.92 (95\% CI: 0.87-0.96), respectively (Figures 3 and 4). We also constructed summary ROCs for both PCT and CRP, the results showed that AUROC of PCT was 0.94 (95\% CI: 0.92-0.96) (Figure 5). The high positive likelihood ratio (LR+: 11.06; 95\% CI: 6.31-19.38) indicates that the PCT test is suitable for a rule-in diagnosis, but its poor negative likelihood ratio (LR-: 0.18, 95\% CI: 0.12-0.27) makes it less useful as a rule-out tool.

As shown in Table 2, seven studies reported diagnostic value of serum CRP levels $[17,19,20,23,24,27,30]$. The pooled sensitivity for CRP was 0.76 (95\% CI: $0.58-0.88$ ), lower than PCT, the specificity was 0.81 (95\% CI: $0.63-$ 0.92), lower than PCT, and the AUROC was 0.85 (95\% CI: 0.82-0.88) (Figure 6). CRP has a poorer LR + (4.01, 95\% CI: $2.16-7.45)$ and LR - (0.29, 95\% CI: 0.17-0.49). Overall, PCT has a higher discriminative capability than CRP in diagnosing peritonitis. The diagnostic OR for PCT was 61.52 (95\% CI: 27.58-137.21), while the diagnostic OR for CRP was 13.54 (95\% CI: 7.25-25.28). There was substantial degree of heterogeneity for PCT $\left(I^{2}=90.08,95 \% \mathrm{CI}\right.$ : 80.35-99.81) and CRP ( $I^{2}=96.81$, 95\% CI: 94.54-99.09).

There were only 5 studies [22,23,28,29,34] reporting accuracy parameters on ascitic PCT, across all settings. We found that a diagnostic OR was 80.93 (95\% CI: 15.26-429.28) for ascitic PCT level to predict peritonitis at sensitivity and specificity of 0.79 (95\% CI: 0.54-0.92) and 0.96 (95\% CI: 0.81-0.99) respectively. The pooled positive likelihood ratio was 17.85 (95\% CI: 4.11-77.59), negative likelihood ratio was 0.22 (95\% CI: 0.09-0.54), and the AUROC was 0.96 (95\% CI, 0.94-0.97). The $I^{2}$ 


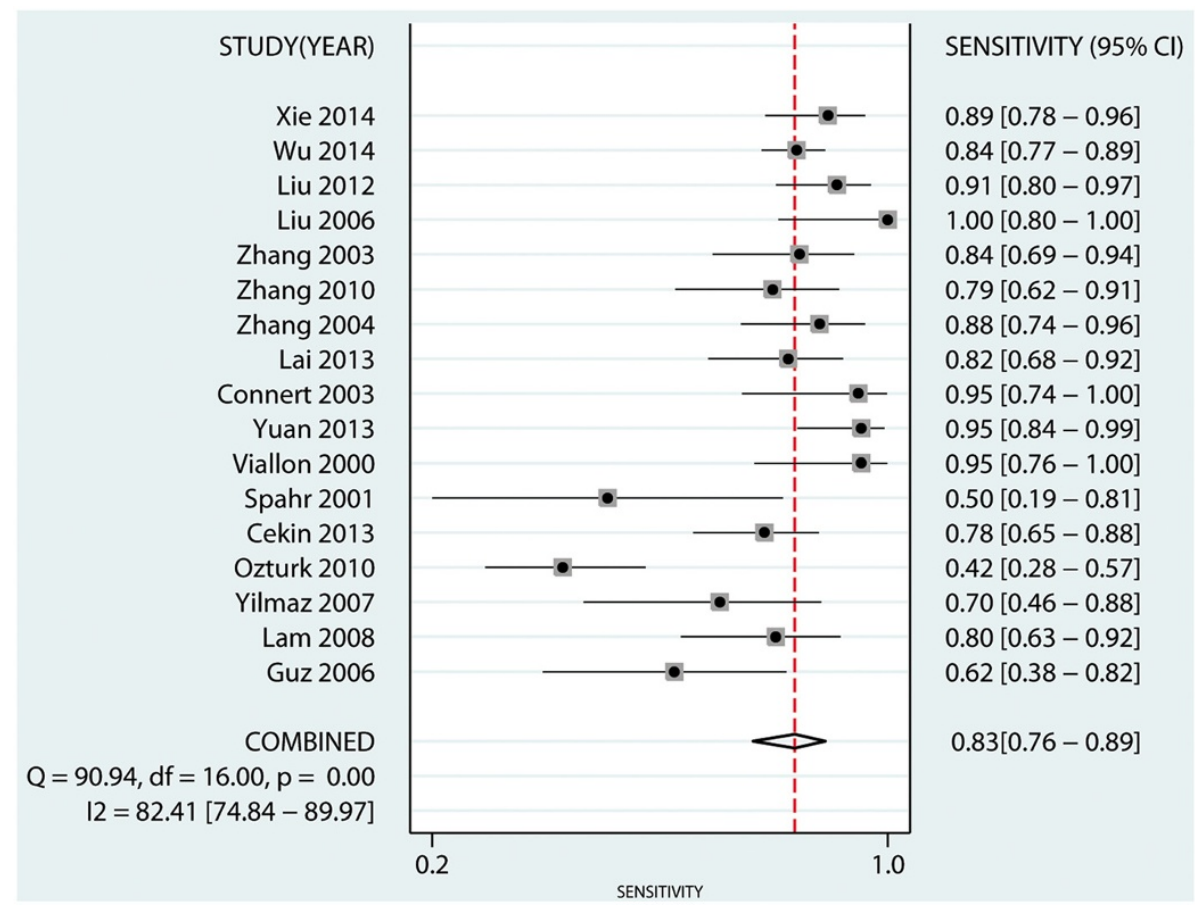

Figure 3 Forest plot of the pooled sensitivity of serum PCT level in predicting bacterial peritonitis across all settings.

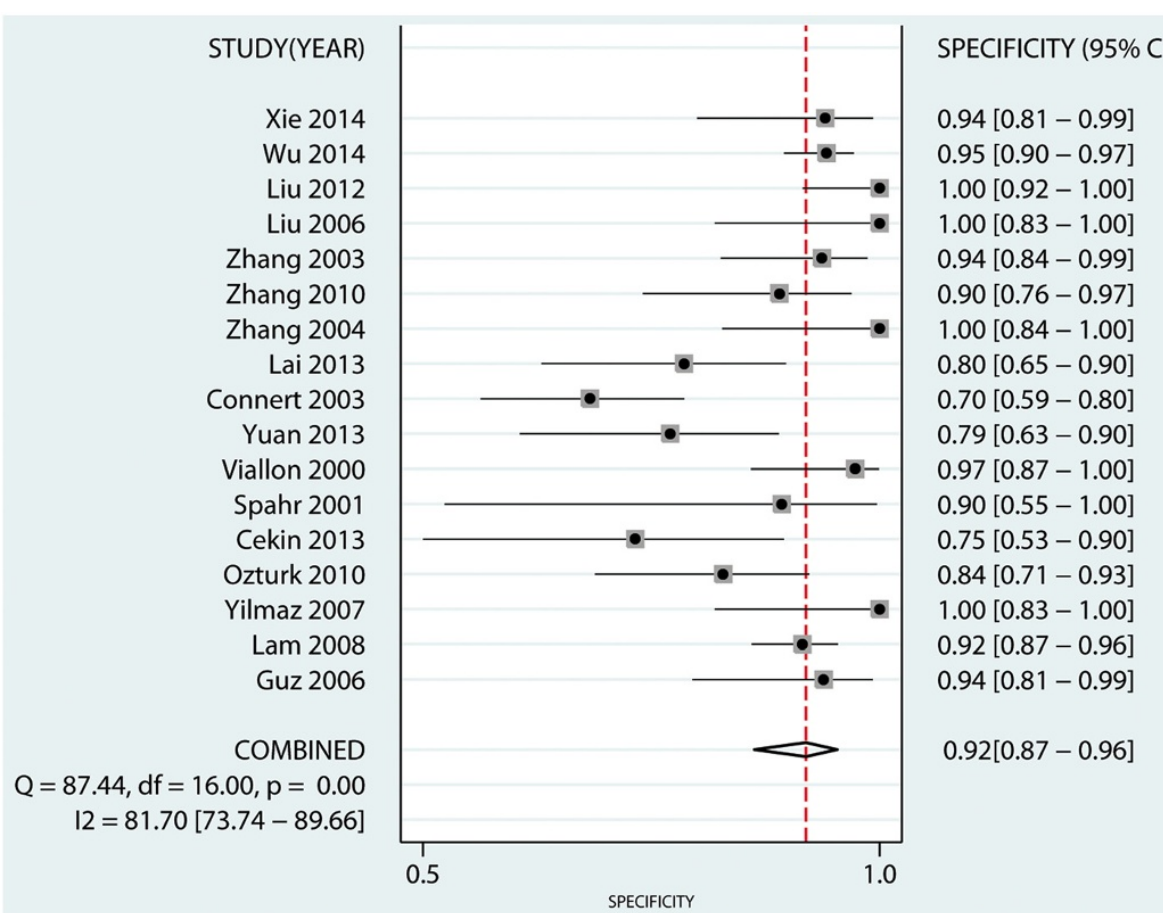

Figure 4 Forest plot of the pooled specificity of serum PCT level in predicting bacterial peritonitis across all settings. 


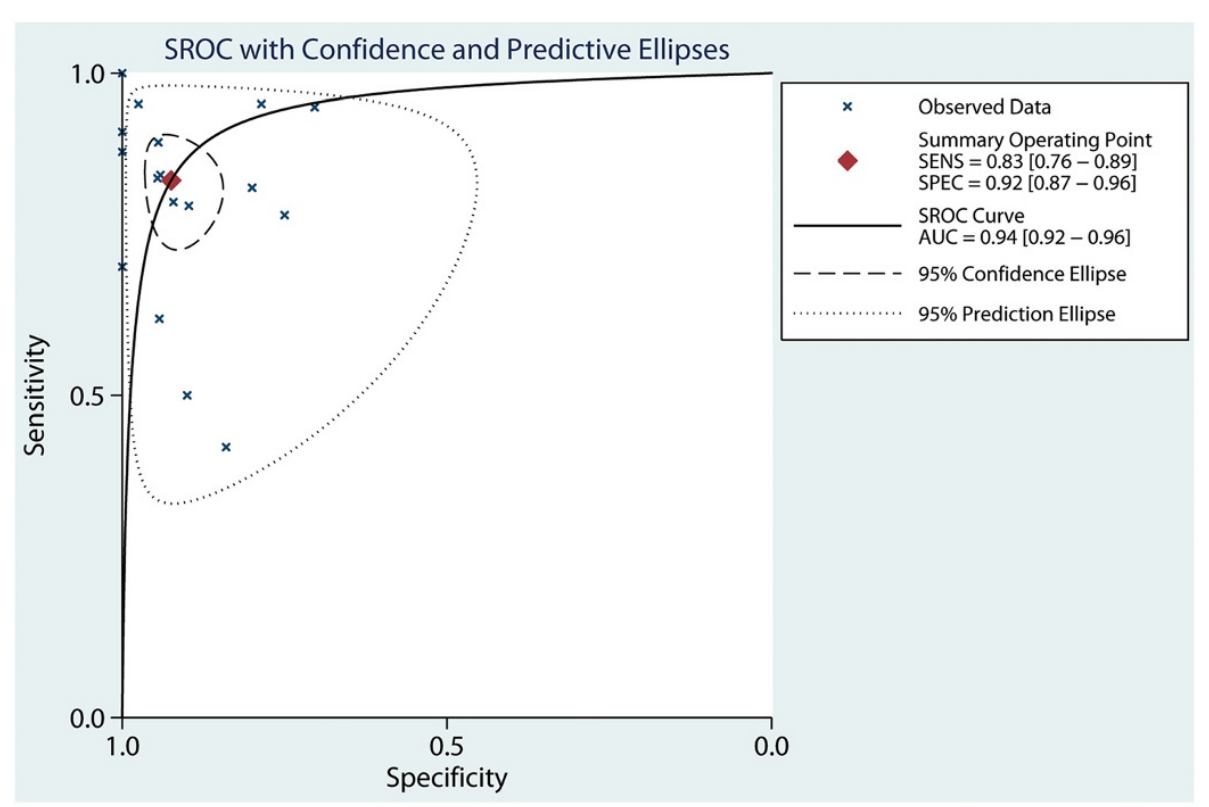

Figure 5 Hierarchical summary receiver operating characteristic plot of serum PCT level to predict bacterial peritonitis across all settings. The curve is represented by the straight line, each of the analyzed studies is represented by a fork. The point estimate to which summary sensitivity and specificity correspond is represented by the diamond shape, and the respective $95 \%$ confidence intervals are represented by the dashed line. Abbreviation: AUC, area under the curve; SENS: summary sensitivity; SPEC: summary specificity. SROC: summary receiver operating characteristic.

statistic was $77.94 \%$, indicating significant heterogeneity across these studies (Table 2).

\section{Subgroup analysis}

Subgroup analyses were performed to explore the source of heterogeneity. Nine studies [17-20,27,31-34] reported test results with the use of a common PCT cutoff value $(0.5 \mathrm{ng} / \mathrm{mL})$. The pooled sensitivity and specificity were 0.81 (95\% CI: $0.68-0.89$ ) and 0.95 (95\% CI: 0.89-0.98) respectively. Three studies $[21,24,33]$ also reported diagnostic accuracy parameters using a lower serum PCT cut-off value $(0.42-0.48 \mathrm{ng} / \mathrm{mL})$, sensitivity increased appreciably $(0.85,95 \%$ CI: $0.80-0.88)$ and the specificity decreased correspondingly $(0.89,95 \%$ CI: $0.79-0.94)$. In contrast, subgroup analysis on parameters using higher cut-off values $(0.615-13.7 \mathrm{ng} / \mathrm{mL})$ showed slightly decreased sensitivity, but increased specificity, compared with the overall estimates $[17,20,22-26,29,30]$.

There were four studies [17-20] carried out on peritoneal dialysis (PD) patients, as shown in Table 2, The value of serum PCT level to predict peritonitis in PD patients (DOR: 18.33; AUROC: 0.89) was substantially lower compared with that in all included patients (DOR: 61.52; AUROC: 0.94). Eleven studies [21-23,25-27,29-32,34] had reported accuracy parameters on serum PCT in cirrhotic patients. The pooled sensitivity and specificity were 0.86 and 0.94 respectively, and the AUROC was 0.91 (95\% CI:
0.89-0.94), indicating that serum PCT also had acceptable predictive performance in cirrhotic patients. The subgroup analyses stratified by the different patient populations (PD and Cirrhotic) using common PCT cut-offs $(0.5 \mathrm{ng} / \mathrm{ml})$ showed that the diagnostic value among PD patients (DOR: 18.33; AUROC: 0.89 ) was substantially lower compared with that in cirrhotic patients (DOR: 245.08; AUROC: 0.94) (shown in Table 2).

As all these included studies using different PCT assays with widely varying functional assay sensitivities (FAS) (shown in Table 1), we have performed the subgroup analyses based on different FAS of the PCT assays, but the result showed that there was no significant difference on the diagnostic value of PCT among trials of different PCT assays (DOR: 65.43; AUROC: 0.95 vs DOR: 71.41; AUROC: 0.95; shown in Table 2). While the subgroup analysis restricted to 8 studies $[17,18,22-25,29,33]$ using the higher sensitive test tool for PCT $(\mathrm{FAS} \leq 0.1 \mathrm{ng} / \mathrm{ml}$ ) showed the sensitivity increased, but the specificity decreased slightly.

We also performed the subgroup analyses based on different dominated language, and the result showed that the value of serum PCT to diagnosis peritonitis in eight trials published in Chinese (DOR: 141.09; AUROC: 0.93) [26,27,29-34] was substantially higher compared with that published in English (DOR: 29.16; AUROC: 0.92; shown in Table 2) [17-25]. 
Table 2 Summary of subgroup analysis of the included studies by different study characteristics

\begin{tabular}{|c|c|c|c|c|c|c|c|c|c|c|}
\hline \multirow[t]{2}{*}{ Variables } & \multirow{2}{*}{$\begin{array}{l}\text { No. of } \\
\text { studies }\end{array}$} & \multirow{2}{*}{$\begin{array}{l}\text { No. of } \\
\text { patients }\end{array}$} & \multirow{2}{*}{$\begin{array}{l}\text { Sensitivity } \\
(95 \% \mathrm{Cl})\end{array}$} & \multirow{2}{*}{$\begin{array}{l}\text { Specificity } \\
\text { (95\% Cl) }\end{array}$} & \multirow{2}{*}{$\begin{array}{l}\text { Diagnostic OR } \\
(95 \% \mathrm{Cl})\end{array}$} & \multirow{2}{*}{$\begin{array}{l}\text { AUROC } \\
(95 \% \mathrm{Cl})\end{array}$} & \multirow[t]{2}{*}{$I^{2}(95 \% \mathrm{Cl})$} & \multicolumn{2}{|c|}{ Likelihood ratio $(95 \% \mathrm{Cl})$} & \multirow{2}{*}{$\begin{array}{l}\text { Publication bias } \\
\text { (Deek's test P) }\end{array}$} \\
\hline & & & & & & & & Positive & Negative & \\
\hline \multicolumn{11}{|l|}{ Serum PCT } \\
\hline Overall analysis & 17 & 1644 & $0.83(0.76-0.89)$ & $0.92(0.87-0.96)$ & $61.52(27.58-137.21)$ & $0.94(0.92-0.96)$ & $90.08(80.35-99.81)$ & 11.06(6.31-19.38) & $0.18(0.12-0.27)$ & 0.973 \\
\hline PD patients & 4 & 391 & $0.64(0.47-0.78)$ & $0.91(0.85-0.94)$ & $18.33(6.32-53.12)$ & $0.89(0.87-0.92)$ & $0.00(0.00-100.00)$ & $7.19(3.75-13.82)$ & $0.39(0.24-0.62)$ & 0.629 \\
\hline Cirrhotic patients & 11 & 807 & $0.86(0.81-0.89)$ & $0.94(0.85-0.97)$ & $85.89(27.31-270.19)$ & $0.91(0.89-0.94)$ & $80.65(58.51-100.00)$ & 13.17(5.27-32.86) & $0.15(0.11-0.21)$ & 0.734 \\
\hline High cut-off PCT value ${ }^{a}$ & 9 & 640 & $0.68(0.44-0.85)$ & $0.97(0.91-0.99)$ & 60.01(24.19-148.85) & $0.95(0.93-0.97)$ & $97.33(95.53-99.13)$ & 20.02(8.29-48.37) & $0.33(0.17-0.64)$ & 0.813 \\
\hline Low cut-off PCT value ${ }^{b}$ & 3 & 529 & $0.85(0.80-0.88)$ & $0.89(0.79-0.94)$ & $42.57(19.72-91.89)$ & $0.86(0.83-0.89)$ & $61.42(13.01-100.00)$ & $7.42(3.89-14.17)$ & $0.17(0.13-0.23)$ & 0.299 \\
\hline Common PCT cut-off value ${ }^{c}$ & 9 & 1072 & $0.81(0.68-0.89)$ & $0.95(0.89-0.98)$ & $75.32(21.13-268.52)$ & $0.95(0.93-0.97)$ & $15.30(0.00-100.00)$ & $15.35(6.67-35.28)$ & $0.20(0.12-0.35)$ & 0.973 \\
\hline Common PCT cut-off in PD & 4 & 391 & $0.64(0.47-0.78)$ & $0.91(0.85-0.94)$ & 18.33(6.32-53.12) & $0.89(0.87-0.92)$ & $0.00(0.00-100.00)$ & $7.19(3.75-13.82)$ & $0.39(0.24-0.62)$ & 0.629 \\
\hline Common PCT cut-off in SBP & 5 & 681 & $0.87(0.78-0.92)$ & $0.97(0.85-0.99)$ & 245.08(26.73-2247.33) & $0.94(0.92-0.96)$ & $60.35(10.58-100.00)$ & $33.02(5.06-215.47)$ & $0.13(0.07-0.23)$ & 0.562 \\
\hline Publication in Chinese & 8 & 905 & $0.86(0.81-0.89)$ & $0.95(0.89-0.98)$ & $141.09(42.44-469.04)$ & $0.93(0.90-0.95)$ & $30.79(0.00-100.00)$ & $20.12(7.64-52.94)$ & $0.14(0.10-0.19)$ & 0.493 \\
\hline Publication in English & 9 & 739 & $0.79(0.63-0.89)$ & $0.89(0.81-0.94)$ & 29.16(11.78-72.17) & $0.92(0.89-0.94)$ & $91.95(84.48-99.43)$ & $6.99(3.97-12.28)$ & $0.24(0.13-0.44)$ & 0.683 \\
\hline $\mathrm{FAS}>0.1 \mathrm{ng} / \mathrm{ml}$ & 9 & 704 & $0.82(0.71-0.90)$ & $0.93(0.85-0.97)$ & 65.43(17.30-247.48) & $0.95(0.92-0.96)$ & $48.24(0.00-100.00)$ & 12.26(5.01-29.99) & $0.18(0.10-0.33)$ & 0.508 \\
\hline $\mathrm{FAS} \leq 0.1 \mathrm{ng} / \mathrm{ml}$ & 8 & 940 & $0.86(0.76-0.92)$ & $0.92(0.85-0.96)$ & $71.41(43.93-116.09)$ & $0.95(0.93-0.97)$ & 89.60(79.27-99.92) & 10.76(6.01-19.26) & $0.15(0.08-0.26)$ & 0.786 \\
\hline \multicolumn{11}{|l|}{ Ascitic PCT } \\
\hline Overall analysis & 5 & 418 & $0.79(0.54-0.92)$ & $0.96(0.81-0.99)$ & $80.93(15.26-429.28)$ & $0.96(0.94-0.97)$ & $77.94(52.08-100.00)$ & 17.85(4.11-77.59) & $0.22(0.09-0.54)$ & 0.075 \\
\hline \multicolumn{11}{|l|}{ Serum CRP } \\
\hline Overall analysis & 7 & 499 & $0.76(0.58-0.88)$ & $0.81(0.63-0.92)$ & $13.54(7.25-25.28)$ & $0.85(0.82-0.88)$ & $96.81(94.54-99.09)$ & $4.01(2.16-7.45)$ & $0.29(0.17-0.49)$ & 0.676 \\
\hline
\end{tabular}

Note: $P C T$ procalcitonin, $P D$ peritoneal dialysis, CRP C-reactive protein, SBP Spontaneous bacterial peritonitis, $F A S$ functional assay sensitivities, $A U R O C$ area under the receiver operating characteristic curve.

${ }^{a}$ High cut-off valu: greater than $0.5 \mathrm{ng} / \mathrm{ml}$; ${ }^{b}$ Low cut-off value: lesser than $0.5 \mathrm{ng} / \mathrm{ml}$; ${ }^{c}$ Common PCT Cut-off value: $=0.5 \mathrm{ng} / \mathrm{ml}$. 


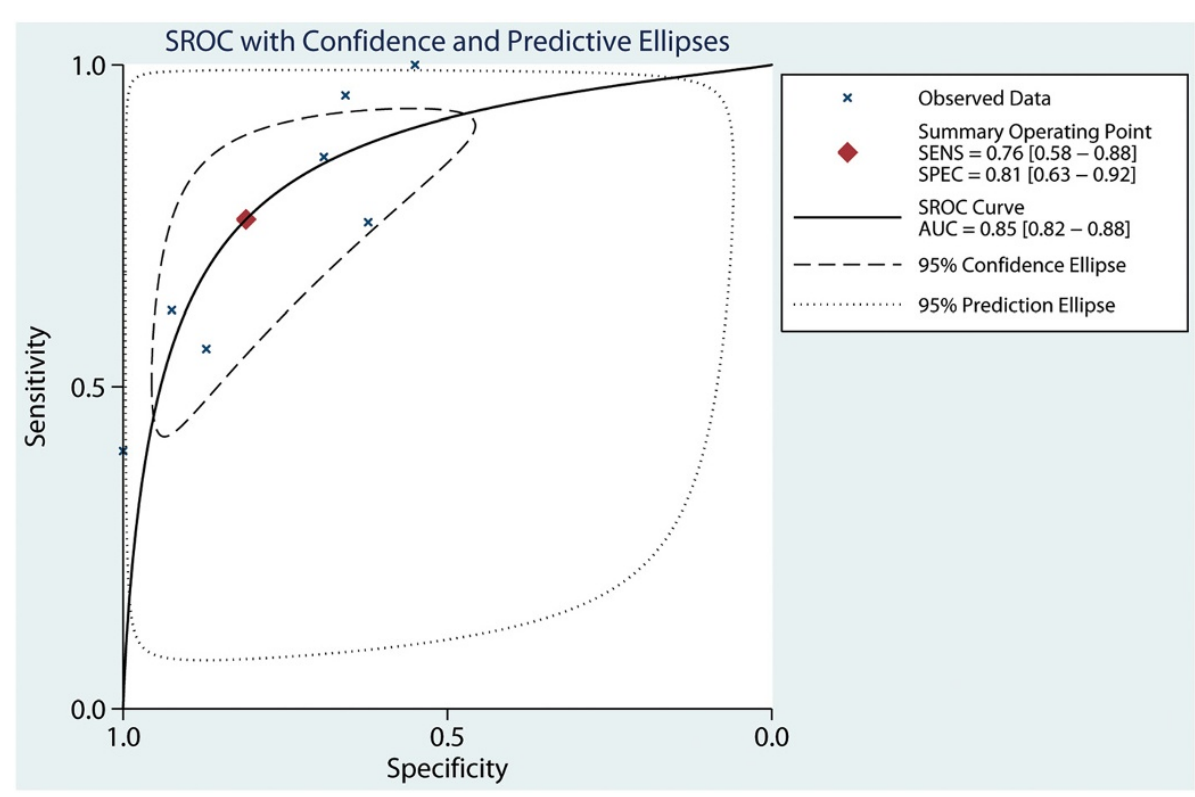

Figure 6 Hierarchical summary receiver operating characteristic plot of serum CRP level to predict bacterial peritonitis across all settings. Abbreviation: AUC, area under the curve; SENS: summary sensitivity; SPEC: summary specificity. SROC: summary receiver operating characteristic.

\section{PCT and long-term adverse outcomes of peritonitis}

Only two studies reported the relationship between longterm survival outcome and the PCT level. Lam et al. [18] found that there was no difference in the survival rate between PD patients with $\mathrm{PCT}>0.38 \mathrm{ng} / \mathrm{mL}$ and patients with PCT $<0.38 \mathrm{ng} / \mathrm{mL}(\mathrm{p}=0.37)$. However, Connert et al. [25] reported that cirrhotic patients with PCT levels above $0.58 \mathrm{ng} / \mathrm{ml}$ were associated with poor survival compared to those with levels below $0.58 \mathrm{ng} / \mathrm{ml}$, and significant differences were found in mean PCT level between patients who died or survivied during the follow-up period $(\mathrm{p}<0.01)$.

\section{Publication bias}

We used funnel plots to assess the publication bias, as shown in Table 2, there was no significant evidence of potential publication bias was noted by Deek's test.

\section{Discussion}

PCT is a polypeptide of 116 amino acids (molecular weight $13 \mathrm{kDa}$ ) with a long half-life of 25-30 h [5]. It was first identified during studies of hypocalcaemia associated with Staphylococcal toxic shock syndrome [35], and then in 1993, its elevated level was found in patients with bacterial infection. It is most commonly produced from neuroendocrine cells in non-thyroidal tissues such as lung, liver or kidney during inflammation [36,37]. Unlike other inflammatory markers (e.g., CRP), PCT level does not respond to viral infection or sterile inflammation. In the serum of healthy individuals, PCT is undetectable $(<0.01 \mathrm{ng} / \mathrm{ml})$ and a value of $>0.5 \mathrm{ng} / \mathrm{ml}$ is considered abnormal [5,36]. Many studies have shown that PCT could rapidly increase in response to bacterial inflammatory stimuli, and it could be recommended as an effective biomarker in the detection and differential diagnosis of inflammatory states [4,6,38,39]. However, there are few meta-analyses on the accurancy of PCT in predicting bacterial peritonitis. In our analysis, which included 1827 patients, we showed that the measurement of serum PCT could provide considerable predictive value (DOR: 61.52; AUROC: 0.94) for the diagnosis of bacterial peritonitis, and that this predictive capacity is better than that provided by CRP (DOR: 13.54; AUROC: 0.85).

There are many types of bacterial peritonitis. In clinical practice, PD related peritonitis and spontaneous bacterial peritonitis (SBP) in cirrhotic patients are most common types in clinical practice. PD represents an important method for the management of uremic patients. Despite a decreasing incidence of PD-related infectious complications over the last couple of decades, peritonitis remains a leading complication and a common cause of infection-related mortality in PD patients [40,41]. Microbiological culture systerm in PD effluent is the gold standard for diagnosis of PD-associated peritonitis, but suffers from high false negative rates and delayed reporting [40]. In this regard, the use of some new reliable diagnostic markers such as PCT can greatly improve the turnaround time of laboratory reports. It has been demonstrated that renal elimination is the major pathway for clearance of PCT [42], and a previous study performed 
by Opatrna et al. [43] showed that the serum levels of PCT were increased in PD patients without overt signs of infection compared with healthy volunteers. But follow-up studies revealed the plasma clearance rate of PCT correlated weakly with renal function dysfunction, and it might not influence clinical decisions based on PCT $[42,44]$. Our meta-analysis also confirmed an acceptable diagnostic accuracy for PCT testing in PD patients (Sensitivity, 0.64; Specificity, 0.91; DOR: 18.33; AUROC: 0.89).

SBP is the most frequent and life-threatening infection in decompensated cirrhotic patients [45]. Owing to an inadequately immune response, clinical manifestations of SBP in cirrhotic patients may be atypical. There is considerable evidence indicating that high PCT levels may be related to infections in cirrhosis [25]. Although the liver is considered as the main source of PCT, a study performed by Bota et al. [46] showed that serum levels of PCT did not significantly decrease in cirrhotic patients. Moreover, PCT had similar predictive power for infection in patients with and without cirrhosis. In accordance with these findings, our meta-analysis also showed that serum PCT testing has a good accuracy for the diagnosis of bacterial peritonitis in cirrhotic patients (Sensitivity, 0.86; Specificity, 0.94; DOR: 85.89; AUROC: 0.91).

Some authors postulated that ascitic PCT might be more sensitive than serum PCT for the early identification of peritonitis, because bacterial infection could trigger peritoneal inflammatory cells to produce PCT, which then may accumulate in the ascitic fluid. In the present study, the pooled analysis of 5 studies [22,23,28,29,34] suggested that ascitic PCT (DOR: 80.93; AUROC: 0.96) to was similar with serum PCT (DOR: 85.89; AUROC: 0.91 ) in diagnosing peritonitis in cirrhotic patients. And Viallon et al. found that PCT detection in ascitic fluid was due to hyperpermeability of peritoneum, while PCT was not synthesized by leucocytes in ascites [23]. These small and in part not significant differences rather supported the assumption of Viallon et al. that PCT detection in the ascitic fluid was the result of a passive shift due to increased vascular permeability instead of an intraperitoneal synthesis. Considering the serious harm for the missed diagnoses of peritonitis, it is not recommended to use ascitic PCT testing as a stand-alone test, and more larger prospective trials are needed to fully elucidate the potential diagnostic value of ascitic PCT.

Fungal peritonitis is a quite uncommon but potentially fatal complication both in peritoneal dialysed [47] and advanced liver cirrhosis patients [48]. The clinical characteristics of fungal peritonitis is not typical and easy to be misdiagnosed. In addition, fungi infections usually result in treatment failure with antibacterial agents and even removing the PD catheter. Early recognition of fungal peritonitis allows for timely and effective therapy with improved outcome, but it is hampered by a lack of a reliable diagnostic tool. There is a significant body of clinical research indicates good diagnostic accuracy for the PCT test for discrimination between invasive fungal infection and bacterial infection $[6,49]$. However, the differential diagnostic value of the PCT testing on fungal peritonitis has not been explored. It is speculated that the PCT testing can provide effective sensitivity and specificity for distinguishing fungal peritonitis from bacterial peritonitis.

The pooled likelihood ratio estimates $\left(\mathrm{LR}^{+}\right.$and $\left.\mathrm{LR}^{-}\right)$ was analyzed to calculate post-test probabilities. In a virtual population with a $20 \%$ prevalence of peritonitis (the actual prevalence of SBP in hospitalized cirrhotic patients with ascites was 10-30\% [50]), use of a serum PCT test with an LR + of 11.06 would increase the posttest probability (positive predictive value) to $72 \%$. In other words, about 3 in 4 patients with positive PCT test results may have confirmed peritonitis. Likewise, in the same population, application of a serum PCT test with a negative likelihood ratio of 0.18 would reduce the posttest probability to $5 \%$, In other words, 1 in 20 patients with negative PCT results may have peritonitis. Using data from the subgroup with a higher PCT cut-off value $(0.615-13.7 \mathrm{ng} / \mathrm{mL})$, a similar calculation indicated a positive post-test probability of $85 \%$ and a negative post-test probability of $7 \%$.

There was substantial heterogeneity detected for the overall results between the eighteen included studies. Potential source of heterogeneity included the different characteristics of the studies, such as methodological quality, admission category, size of the study populations, different reference standards in PD or cirrhotic patients for peritonitis (ascitic PMN $>50 / \mathrm{mm}^{3}$ or $>250 / \mathrm{mm}^{3}$, respectively), different countries and different human race and different methods used for measurement of PCT (LUMItest, ECLIA and the Semi-quantitative PCT-Q assay systems). And other unrecorded differences among these studies might also contribute to the heterogeneity. Evaluation with individual patient data or meta-regression would help in this analysis of the sources of heterogeneity. However, the meta-regression would have to adjust for factors at individual patient level, which were not available at present, therefore it limited our ability to further evaluate heterogeneity. On the other hand, using more homogeneous trials could solve this difficulty, but it could induce selection bias.

There are several potential limitations to our study that should be addressed.

First, in our meta-analysis, various PCT testing assay tools and various PCT cut-off values were used in different included studies, and sensitivities and specificities 
varied between studies. We performed subgroup analysis and constructed the HSROC curve and calculated AUROC to diminish the influence of different PCT assays and cut-off values effect. Despite the adjustment by bivariate model, there might be residual influence on the accuracy of pooled diagnostic parameters. Second, most of the studies have a case-control design, it has been demonstrated that the case-control design could over-estimate the accuracy of a diagnostic test [51], therefore more larger prospective trials should be performed to elucidate the diagnostic value of PCT. Third, as mentioned before, our study suffered from moderate heterogeneity, mainly owing to different patients characteristics, and different definitions of peritonitis. Fourth, despite no significant publication bias was detected, however, this study included 9 low-quality Chinese language trials, which might lead to an overestimation of overall diagnostic accuracy of PCT, especially because positive studies were more easily reported.

\section{Conclusion}

In conclusion, our meta-analysis shows that PCT is a helpful marker in identifying bacterial peritonitis, Although PCT performs as well in PD patients as in cirrhotic or severe hepatitis patients, use of a common cut-off value may further enhance accuracy. Compared with CRP, PCT is superior in the diagnosis of bacterial peritonitis. However, it is important to note that PCT cannot be recommended as a "gold standard" test for peritonitis up to now, and should be interpreted in combination with other clinical, analytical, and/or microbiological data. Given the limits of PCT as a single marker, additional large prospective studies should determine its diagnostic value in bacterial peritonitis, when interpreted in association with other biomarkers.

\section{Competing interests}

The authors report no competing interests. The authors alone are responsible for the content and writing of the paper.

\section{Authors' contributions}

SKY and LX wrote the manuscript and performed the statistical analysis, $\mathrm{HZ}$ participated in the design of the study and guided the statistical analysis, $X X X$, and PAS generated the data for the manuscript, FYL edited the manuscript, LS conceived of the study, and participated in its design and coordination and helped to draft the manuscript. All authors read and approved the final manuscript.

\section{Acknowledgements}

Supported by grants from the National Natural Sciences Foundation of China (81270812, 81100541), Ph.D programs foundation of ministry of Education of China (2011062110012). Furong Scholars Fund from Hunan Province Education Department.

\section{Author details}

${ }^{1}$ Department of Nephrology, The Second Xiangya Hospital, Kidney Institute of Central South University, Changsha, Hunan 410011, China. ${ }^{2}$ Department of Nephrology, The Third Xiangya Hospital, Central South University, Changsha, Hunan Province 410013, China.
Received: 24 December 2013 Accepted: 13 August 2014

Published: 22 August 2014

\section{References}

1. Ordonez CA, Puyana JC: Management of peritonitis in the critically ill patient. Surg Clin North Am 2006, 86(6):1323-1349.

2. Davenport A: Peritonitis remains the major clinical complication of peritoneal dialysis: the London, UK, peritonitis audit 2002-2003. Perit Dial Int 2009, 29(3):297-302.

3. Bernardi M: Spontaneous bacterial peritonitis: from pathophysiology to prevention. Intern Emerg Med 2010, 5(Suppl 1):S37-S44.

4. Wacker C, Prkno A, Brunkhorst FM, Schlattmann P: Procalcitonin as a diagnostic marker for sepsis: a systematic review and meta-analysis. Lancet Infect Dis 2013, 13(5):426-435.

5. Irwin AD, Carrol ED: Procalcitonin. Arch Dis Child Educ Pract Ed 2011, 96(6):228-233.

6. Dou YH, Du JK, Liu HL, Shong XD: The role of procalcitonin in the identification of invasive fungal infection-a systemic review and meta-analysis. Diagn Microbiol Infect Dis 2013, 76(4):464-469.

7. Su DH, Zhuo C, Liao K, Cheng WB, Cheng H, Zhao XF: Value of serum procalcitonin levels in predicting spontaneous bacterial peritonitis. Hepatogastroenterology 2013, 60(124):641-646.

8. Rosman AS, Korsten MA: Application of summary receiver operating characteristics (sROC) analysis to diagnostic clinical testing. Adv Med Sci 2007, 52:76-82.

9. Stroup DF, Berlin JA, Morton SC, Olkin I, Williamson GD, Rennie D, Moher D, Becker BJ, Sipe TA, Thacker SB: Meta-analysis of observational studies in epidemiology: a proposal for reporting. Meta-analysis Of Observational Studies in Epidemiology (MOOSE) group. JAMA 2000, 283(15):2008-2012.

10. Whiting P, Rutjes AW, Reitsma JB, Bossuyt PM, Kleijnen J: The development of QUADAS: a tool for the quality assessment of studies of diagnostic accuracy included in systematic reviews. BMC Med Res Methodol 2003, $3: 25$.

11. Schisterman EF, Perkins NJ, Liu A, Bondell H: Optimal cut-point and its corresponding Youden Index to discriminate individuals using pooled blood samples. Epidemiology 2005, 16(1):73-81.

12. van Houwelingen $H C$, Arends LR, Stijnen $T$ : Advanced methods in meta-analysis: multivariate approach and meta-regression. Stat Med 2002, 21(4):589-624.

13. Reitsma JB, Glas AS, Rutjes AW, Scholten RJ, Bossuyt PM, Zwinderman AH: Bivariate analysis of sensitivity and specificity produces informative summary measures in diagnostic reviews. J Clin Epidemiol 2005, 58(10):982-990.

14. Chappell FM, Raab GM, Wardlaw JM: When are summary ROC curves appropriate for diagnostic meta-analyses? Stat Med 2009, 28(21):2653-2668

15. Higgins JP, Thompson SG: Quantifying heterogeneity in a meta-analysis. Stat Med 2002, 21(11):1539-1558.

16. Deeks JJ, Macaskill P, Irwig L: The performance of tests of publication bias and other sample size effects in systematic reviews of diagnostic test accuracy was assessed. J Clin Epidemiol 2005, 58(9):882-893.

17. Guz G, Colak B, Hizel K, Reis KA, Erten Y, Bali M, Sindel S: Procalcitonin and conventional markers of inflammation in peritoneal dialysis patients and peritonitis. Perit Dial Int 2006, 26(2):240-248.

18. Lam MF, Leung JC, Lam CW, Tse KC, Lo WK, Lui SL, Chan TM, Tam S, Lai KN: Procalcitonin fails to differentiate inflammatory status or predict longterm outcomes in peritoneal dialysis-associated peritonitis. Perit Dial Int 2008, 28(4):377-384.

19. Yilmaz FM, Yilmaz G, Akay H, Duranay M, Yucel D: Evaluation of a card test for procalcitonin in continuous ambulatory peritoneal dialysis peritonitis. Ann Clin Biochem 2007, 44(Pt 5):482-484.

20. Özturk R, Yilmaz GR, Bulut C, Parpucu H, Kinikli S, Duranay M, Demiröz AP: Assessment of procalcitonin and other inflammatory markers in peritoneal dialysis-related peritonitis. Turk J Med Sci 2010, 40(20):199-206.

21. Cekin Y, Cekin AH, Duman A, Yilmaz U, Yesil B, Yolcular BO: The role of serum procalcitonin levels in predicting ascitic fluid infection in hospitalized cirrhotic and non-cirrhotic patients. Int J Med Sci 2013, 10(10):1367-1374.

22. Spahr L, Morard I, Hadengue A, Vadas L, Pugin J: Procalcitonin is not an accurate marker of spontaneous bacterial peritonitis in patients with cirrhosis. Hepatogastroenterology 2001, 48(38):502-505. 
23. Viallon A, Zeni F, Pouzet V, Lambert C, Quenet S, Aubert G, Guyomarch S, Tardy B, Bertrand JC: Serum and ascitic procalcitonin levels in cirrhotic patients with spontaneous bacterial peritonitis: diagnostic value and relationship to pro-inflammatory cytokines. Intensive Care Med 2000, 26(8):1082-1088

24. Yuan LY, Ke ZQ, Wang M, Li Y: Procalcitonin and C-reactive protein in the diagnosis and prediction of spontaneous bacterial peritonitis associated with chronic severe hepatitis B. Ann Lab Med 2013, 33(6):449-454.

25. Connert S, Stremmel W, Elsing C: Procalcitonin is a valid marker of infection in decompensated cirrhosis. Z Gastroenterol 2003, 41(2):165-170.

26. Zhang W, Zhang SL, Wang HB: Clinical value of detection of plasma procalcitonin, TNFa and IL-6 in liver cirrhotic patients. Chin J Infect Dis 2003, 21(1):47-49.

27. Lai JL: Clinical significance of the combination detection of Procalcitonin and C-reactive protein in the cirrhosis patients complicated with spontaneous bacterial peritonitis. Fujian Med J 2013, 35(1):65-67.

28. Yang $\mathrm{CH}$, Shen $\mathrm{Y}$, Fan X: The role of ascitic procalcitonin, TNFa and LPS in predicting spontaneous bacterial peritonitis in cirrhotic patients. Modern Practical Medicine 2007, 19(3):208-210

29. Zhang W, Gao ZQ, Zhang SL: Clinical significance of detection of plasma and ascitic procalcitonin in cirrhotic patients with spontaneous bacterial peritonitis. Chin J Clini Hepatol 2004, 20(3):174-176.

30. Zhang Y, Zhang ZG: Clinical value of procalcitonin and C-reactive protein test in liver cirrhotic patients with spontaneous bacterial peritonitis. Clinical Focus 2010, 25(8):665-669.

31. Liu JC, Wang ZS, Xue X, Gu JM: Diagonosis value of serum procalcitonin in cirrhotic patients with sponaneous bacterial peritonitis. J Dalian Med Univ 2006, 3(28):201-203.

32. Liu ZJ, Cai HD, Zhang YH: Alteration of serum procalcitonin levels in liver cirrhosis patients complicated with spontaneous bacterial peritonitis. Chin J Exp Clin Infect Dis 2012, 6(3):238-241.

33. Wu J, Jiang F, Zeng T, Xu H, Lei Y, Zhong S, Zhou Z, Ren H: Role of serum procalcitonin assay for diagnosis of spontaneous bacterial peritonitis in end-stage liver diseases. Zhongguo Yi Xue Ke Xue Yuan Xue Bao 2014 36(1):37-41.

34. Xie F, Liu ZX, Chen L: Clinical significance of detecting levels of serum and ascitic PCT in patients with liver cirrhosis complicating spontaneous bacterial peritonitis. Int J Lab Med 2014, 35(5):525-527.

35. Chesney RW, McCarron DM, Haddad JG, Hawker CD, DiBella FP, Chesney PJ, Davis JP: Pathogenic mechanisms of the hypocalcemia of the staphylococcal toxic-shock syndrome. J Lab Clin Med 1983, 101(4):576-585.

36. Maruna P, Nedelnikova K, Gurlich R: Physiology and genetics of procalcitonin. Physiol Res 2000, 49(Suppl 1):S57-S61.

37. Morgenthaler NG, Struck J, Chancerelle Y, Weglohner W, Agay D, Bohuon C, Suarez-Domenech V, Bergmann A, Muller B: Production of procalcitonin (PCT) in non-thyroidal tissue after LPS injection. Horm Metab Res 2003, 35(5):290-295.

38. Yu CW, Juan LI, Hsu SC, Chen CK, Wu CW, Lee CC, Wu JY: Role of procalcitonin in the diagnosis of infective endocarditis: a meta-analysis. Am J Emerg Med 2013, 31(6):935-941.

39. Shen CJ, Wu MS, Lin KH, Lin WL, Chen HC, Wu JY, Lee MC, Lee CC: The use of procalcitonin in the diagnosis of bone and joint infection: a systemic review and meta-analysis. Eur J Clin Microbiol Infect Dis 2013, 32(6):807-814

40. Akoh JA: Peritoneal dialysis associated infections: An update on diagnosis and management. World J Nephrol 2012, 1(4):106-122.

41. Song $Y$, Wu J, Yan $H$, Chen J: Peritoneal dialysis-associated nontuberculous mycobacterium peritonitis: a systematic review of reported cases. Nephrol Dial Transplant 2012, 27(4):1639-1644.

42. Meisner M, Lohs T, Huettemann E, Schmidt J, Hueller M, Reinhart K: The plasma elimination rate and urinary secretion of procalcitonin in patients with normal and impaired renal function. Eur J Anaesthesiol 2001, 18(2):79-87.

43. Opatrna S, Klaboch J, Opatrny K Jr, Holubec L, Tomsu M, Sefrna F, Topolcan O: Procalcitonin levels in peritoneal dialysis patients. Perit Dial Int 2005, 25(5):470-472.

44. Lu XL, Xiao ZH, Yang MY, Zhu YM: Diagnostic value of serum procalcitonin in patients with chronic renal insufficiency: a systematic review and meta-analysis. Nephrol Dial Transplant 2013, 28(1):122-129.

45. Wiest R, Krag A, Gerbes A: Spontaneous bacterial peritonitis: recent guidelines and beyond. Gut 2012, 61(2):297-310.
46. Bota DP, Van Nuffelen M, Zakariah AN, Vincent JL: Serum levels of C-reactive protein and procalcitonin in critically ill patients with cirrhosis of the liver. J Lab Clin Med 2005, 146(6):347-351.

47. Basturk T, Koc Y, Unsal A, Ahbap E, Sakaci T, Yildiz I, Kayabasi H, Sevinc M, Kose $S$, Arar A: Fungal peritonitis in peritoneal dialysis: a 10 year retrospective analysis in a single center. Eur Rev Med Pharmacol Sci 2012 16(12):1696-1700.

48. Hwang SY, Yu SJ, Lee JH, Kim JS, Yoon JW, Kim YJ, Yoon JH, Kim EC, Lee HS: Spontaneous fungal peritonitis: a severe complication in patients with advanced liver cirrhosis. Eur J Clin Microbiol Infect Dis 2014, 33(2):259-264.

49. Petrikkos GL, Christofilopoulou SA, Tentolouris NK, Charvalos EA, Kosmidis CJ, Daikos GL: Value of measuring serum procalcitonin, C-reactive protein, and mannan antigens to distinguish fungal from bacterial infections. Eur J Clin Microbiol Infect Dis 2005, 24(4):272-275.

50. Rimola A, Garcia-Tsao G, Navasa M, Piddock LJ, Planas R, Bernard B, Inadomi JM: Diagnosis, treatment and prophylaxis of spontaneous bacterial peritonitis: a consensus document. International Ascites Club J Hepatol 2000, 32(1):142-153.

51. Leeflang MM, Deeks JJ, Gatsonis C, Bossuyt PM: Systematic reviews of diagnostic test accuracy. Ann Intern Med 2008, 149(12):889-897.

doi:10.1186/1471-2334-14-452

Cite this article as: Yang et al: Significance of serum procalcitonin as biomarker for detection of bacterial peritonitis: a systematic review and meta-analysis. BMC Infectious Diseases 2014 14:452.

\section{Submit your next manuscript to BioMed Central and take full advantage of:}

- Convenient online submission

- Thorough peer review

- No space constraints or color figure charges

- Immediate publication on acceptance

- Inclusion in PubMed, CAS, Scopus and Google Scholar

- Research which is freely available for redistribution

Submit your manuscript at www.biomedcentral.com/submit
C) BioMed Central 